\title{
A DINÂMICA DAS POLÍTICAS PÚBLICAS DE DESENVOLVIMENTO RURAL E SUA INCIDÊNCIA TERRITORIAL: UMA ANÁLISE DO PRONAF NO TERRITÓRIO VALE DO MUCURI/MG
}

Sandro Pereira Silva ${ }^{1}$

\begin{abstract}
Resumo
Este estudo tem como objetivo verificar a dinâmica das políticas públicas de desenvolvimento rural e sua incidência territorial. Para isso, analisou-se os arranjos institucionais formados a partir da incidência do PRONAF em um âmbito territorial e as estratégias desses atores envolvidos para potencializar a ação do programa em seus municípios, no período de 1999 a 2010. As análises referentes à evolução do PRONAF nos municípios do território apontam uma ampliação considerável tanto em termos de recursos como em termos de número de contratos no período. No entanto, os elementos analisados neste documento evidenciam que existem ainda desafios a serem vencidos no território para potencializar e qualificar o acesso aos créditos do PRONAF, inclusive quanto à articulação com outras políticas públicas voltadas ao segmento da agricultura familiar.
\end{abstract}

Palavras chave: políticas públicas; desenvolvimento rural; incidência territorial; agricultura familiar; PRONAF.

\section{THE DYNAMICS OF RURAL DEVELOPMENT POLICIES AND THEIR TERRITORIAL INCIDENCE: AN ANALYSIS OF THE PRONAF IN TERRITORY VALE DO MUCURI/MG}

\begin{abstract}
This paper aims to determine the dynamics of public policies on rural development and territorial incidence. For this, we analyzed the institutional arrangements formed from the incidence of PRONAF in a territorial scope and the strategies of stakeholders to enhance the action of the program in their counties, from 1999 to 2008. The analyzes regarding the evolution of the municipalities of the territory PRONAF show a considerable increase both in terms of resources and in terms of number of contracts in the period. However, the evidence examined in this paper show that there are still challenges to be overcome in the territory to enhance and qualify the access to credits PRONAF, even as the liaison with other public policies aimed at the segment of family farming.
\end{abstract}

Keywords: public policy, rural development; family farming; territorial incidence; PRONAF.

\footnotetext{
${ }^{1}$ Graduação e mestrado em Ciências Econômicas pela Universidade Federal de Viçosa. Doutorando em Políticas Públicas e Estratégia de Desenvolvimento pela Universidade Federal do Rio de Janeiro. Email: sandroecbr@yahoo.com.br
} 


\section{INTRODUÇÃO}

Este trabalho tem como objetivo principal verificar a dinâmica das políticas públicas de desenvolvimento rural e sua incidência territorial. Para tanto, analisou-se os arranjos institucionais formados a partir da incidência do Programa Nacional de Fortalecimento da Agricultura Familiar (PRONAF) em um âmbito territorial e as estratégias dos atores envolvidos para potencializar a ação do programa em seus municípios. Como recorte geográfico foi escolhido o Território Vale do Mucuri, no estado de Minas Gerais. Analisou-se a função exercida por cada um dos atores sociais envolvidos no PRONAF e demais políticas de fortalecimento da agricultura familiar nos municípios do Vale do Mucuri (assistência técnica, comercialização, reforma agrária e regularização fundiária), especialmente para o período de 2000 a 2010. Entre esses atores estão: os Sindicatos de Trabalhadores Rurais, as Prefeituras Municipais, as entidades de ATER, os agentes financeiros e as organizações da sociedade civil.

Partiu-se da hipótese de que a tendência à descentralização na implementação e execução das políticas sociais no Brasil promove uma maior dinâmica relacional entre os atores locais, proporcionando um adensamento do conjunto de laços e relacionamentos presentes tanto no nível interno como no externo. Essa inter-relação permite o surgimento de redes sociais de cooperação entre as organizações de outros municípios vizinhos que apresentam laços de identidade e coesão territorial, formando o "território de incidência" dessas políticas, isto é, o espaço geográfico onde se concentram público beneficiário e organizações mediadoras para a implementação das políticas públicas. Toda essa interação permite a constituição de um arranjo institucional favorável para uma intervenção mais qualitativa das políticas públicas, pois propicia maior protagonismo e empoderamento dos atores locais e diminui os custos de transação para o desenvolvimento de novos projetos locais. Outros trabalhos que abordam a incidência territorial de políticas públicas envolvendo a temática da agricultura familiar podem ser consultados em Oliveira e Silva (2013) e Silva (2014).

Para se chegar aos objetivos esperados, realizou-se, primeiramente, uma análise documental junto aos principais documentos de referência do Território Vale do Mucuri (TVM), elaborados com a participação dos integrantes de seu Conselho de Desenvolvimento Territorial (CODETER). Outras fontes de dados oficiais, como a Secretaria de Agricultura Familiar do Ministério do Desenvolvimento Agrário (SAF/MDA) e o Instituto Nacional de Colonização e Reforma Agrária (INCRA) também foram consultadas, além de relatórios técnicos e entrevistas junto a representantes do CODETER/TVM. De maneira complementar, fez-se uso da observação participante em reuniões ordinárias e outros eventos promovidos pelo CODETER/TVM, além de entrevistas informais com conselheiros envolvidos diretamente com as políticas de desenvolvimento rural, bem como técnicos agrícolas e agricultores familiares que atuam no território.

\section{AGRICULTURA FAMILIAR, POLÍTICAS PÚBLICAS E TERRITORIALIZAÇÃO}

A partir dos anos finais do século XX, emergiram no meio acadêmico, político e na sociedade civil em geral, vários debates acerca da necessidade de se pensar o desenvolvimento de uma maneira sustentável. Iniciou-se uma maior preocupação com as questões ambientais, em especial, aquelas relacionadas à preservação dos recursos naturais e sua disponibilidade às gerações futuras. Nesse cenário, surgiram diversas deliberações acerca do novo papel do rural, com três 
importantes destaques encontrados na literatura sobre o tema. O primeiro refere-se à grande heterogeneidade cultural, social e econômica que a agricultura familiar brasileira representa, podendo variar desde o campesinato tradicional até a pequena produção mecanizada ${ }^{2}$. Buainain (2006) enfatizou a diversidade de atores que compõem a agricultura familiar e que diferem entre si em muitos aspectos:

A diferenciação dos agricultores familiares está associada à própria formação dos grupos ao longo da história, a heranças culturais variadas, à experiência profissional e de vida particulares, ao acesso e à disponibilidade diferenciada de um conjunto de fatores, entre os quais os recursos naturais, o capital humano, o capital social e assim por diante. [...]

Também se diferenciam em relação às potencialidades $e$ restrições associadas tanto à disponibilidade de recursos e de capacitação/aprendizado adquirido, como à inserção ambiental e socioeconômica que podem variar radicalmente entre grupos de produtores em função de um conjunto de variáveis, desde a localização até as características particulares do meio-ambiente no qual estão inseridos. O universo diferenciado de agricultores familiares está composto de grupos com interesses particulares, estratégias próprias de sobrevivência e de produção, que regem de maneira diferenciada a desafios, oportunidades e restrições semelhantes e que, portanto, demandam tratamento compatível com as diferenças ( $p$. 1516).

Mesmo com toda a diversidade desse tipo de organização sócio-produtiva no meio rural brasileiro, algumas características podem ser identificadas como comuns e identificadoras da categoria dos agricultores familiares, entre as quais estão a independência relativa de insumos externos à propriedade e o fato da produção agrícola estar condicionada às necessidades do grupo familiar (SILVA, 2015). Dessa forma, o termo agricultura familiar passou a designar, ao mesmo tempo, um modelo de organização da unidade de produção agrícola e uma identidade social de um grupo multifacetado e espalhado por todo o território nacional.

O segundo destaque diz respeito ao seu caráter multifuncional, associado ao reconhecimento social de que a agricultura familiar exerce um papel que vai além da mera produção de produtos agrícolas, destinados à alimentação humana e animal, além de servir de matéria prima para a indústria. A atividade agrícola também é responsável por outros bens imateriais e não mercantis apropriados pelas populações urbanas e rurais, sejam eles de caráter privado ou público. A figura a seguir esquematiza bem essa ideia sobre a multifuncionalidade agrícola com base na diversidade dos bens gerados.

\footnotetext{
${ }^{2}$ A categoria social da agricultura familiar assume proporções nada desprezíveis para a formulação de um projeto de desenvolvimento no país, já que cerca de $90 \%$ de seus 5.807 municípios têm na atividade agrícola a base de sua economia e, malgrado o tratamento desigual sofrido em termos de favorecimentos políticos, a agricultura familiar responde por mais de $80 \%$ dos estabelecimentos rurais, empregando em torno de $75 \%$ da população economicamente ativa na agricultura (SILVA, 2008).
} 


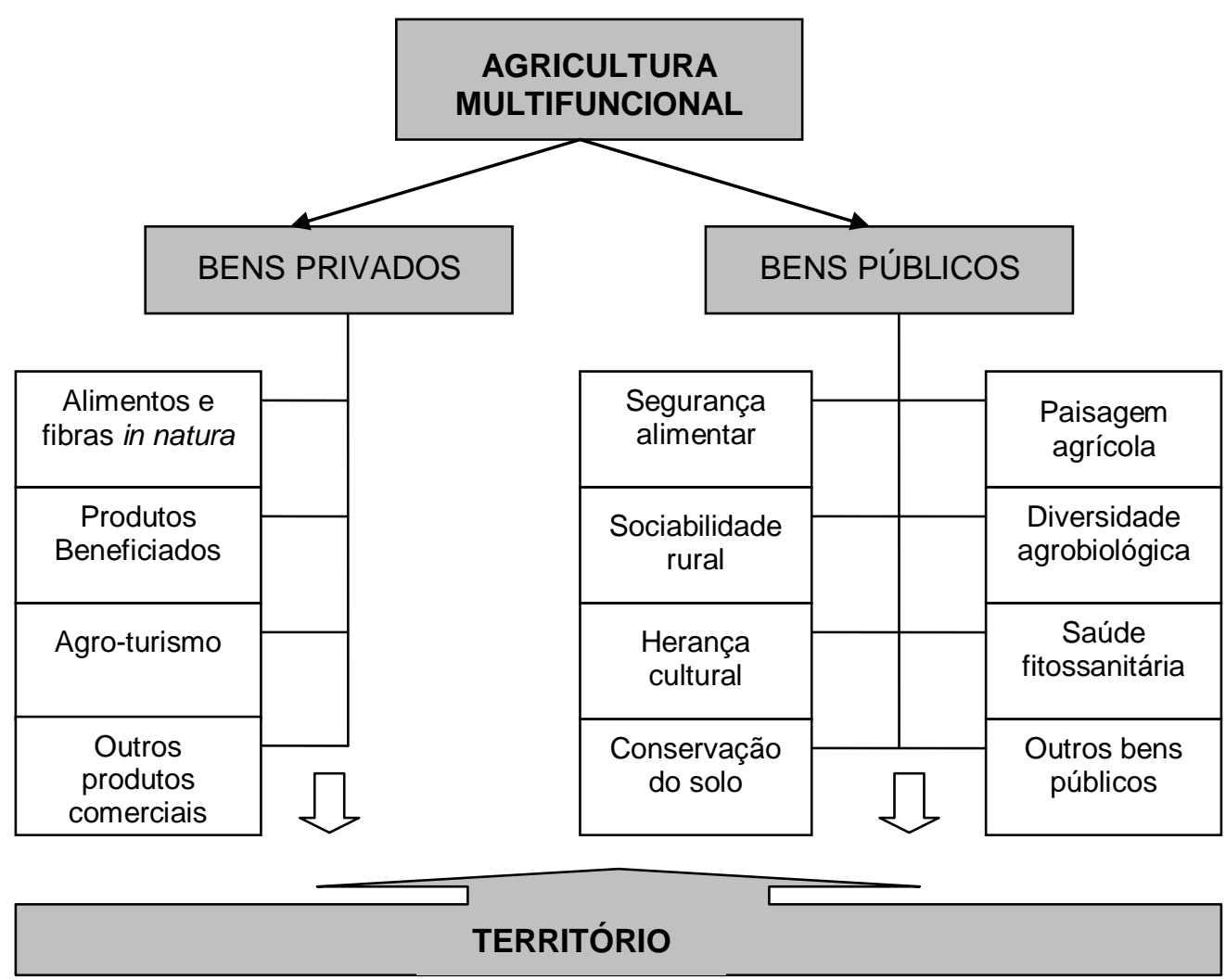

Figura 1 - Esquema analítico da multifuncionalidade agrícola

Fonte: Silva (2015). Adaptado de Maluf (2001).

Para Carneiro e Maluf (2003), o enfoque da multifuncionalidade da agricultura familiar rompe com o caráter eminentemente setorial e amplia o campo das funções sociais que Ihe são atribuídas, ao contemplar três níveis de análise que correspondem, respectivamente, às famílias rurais ${ }^{3}$, ao território e à sociedade. Essa visão permite recolocar os termos em que a agricultura é inserida na problemática do desenvolvimento territorial sustentável, ao mesmo tempo em que oferece as bases para que sejam repensadas as políticas públicas e transferências sociais de benefícios aos agricultores.

O terceiro destaque está relacionado a um posicionamento contrário à dicotomia rural-urbano na elaboração de projetos de desenvolvimento, que negligencia as relações sociais que são desenvolvidas na prática em decorrência da integração do rural com o urbano, seja em termos populacionais, ocupacional e de valores (MEIJA, 2006).

Essa interligação entre os espaços rurais e urbanos é denominada por Favareto (2007) de "dinâmicas territoriais de desenvolvimento". Para uma intervenção sob essas dinâmicas, o autor realçou a necessidade de entender as

\footnotetext{
${ }^{3}$ Por família rural entende-se a unidade que se reproduz em regime de economia familiar e que desenvolve qualquer processo biológico sobre um pedaço de terra, "situada" num território com determinadas características socioeconômicas, culturais e ambientais (CARNEIRO; MALUF, 2003).
} 
articulações entre suas formas de produção e as características morfológicas dos tecidos sociais locais. A dicotomia rural-urbano passa então a ser abordada a partir do entendimento de suas relações de oposição e complementaridade. Assim, a dimensão territorial do desenvolvimento resulta de formas específicas de interação social, da capacidade dos indivíduos, das empresas, do poder público e das organizações locais em promover ligações dinâmicas, capazes de valorizar seus conhecimentos e suas tradições.

A representação dos territórios é dada como resultado de formas de articulação social em espaços heterogêneos, sob os quais são constituídos os elementos de identidade territorial, uma vez que a prática social é desenvolvida em um espaço geográfico determinado. O território, portanto, não se constitui apenas sob uma base material ou física; ele também é composto de um referencial de elaboração simbólica onde convergem distintas dimensões (social, política, econômica e cultural) (SOUZA; SILVA; SILVA, 2012; SILVA; DIAS; SILVA, 2014).

Com base nesse entendimento, o desenvolvimento rural, pensado de forma sustentável, tem como meta principal estimular e favorecer os processos de ordenamento territorial e de desenvolvimento da sociedade em geral. Nesses termos, o conceito de território adotado pelo Conselho Nacional de Desenvolvimento Rural Sustentável (MDA, 2005, p. 28) define-se como:

[...] um espaço físico, geograficamente definido, geralmente contínuo, compreendendo cidades e campos, caracterizado por critérios multidimensionais, tais como o ambiente, a economia, a sociedade, a cultura, a política e as instituições, e uma população, com grupos sociais relativamente distintos, que se relacionam interna e externamente por meio de processos específicos, onde se pode distinguir um ou mais elementos que indicam identidade e coesão social, cultural e territorial.

Esses elementos identificados devem propiciar um sentimento de pertencimento aos diversos grupos locais espalhados pelos municípios que o compõem de forma a consolidar uma maior coesão social e territorial entre seus atores sociais. Contudo, no meio rural brasileiro o histórico sobre o planejamento e a execução das políticas públicas apresenta uma leitura apenas parcial da realidade do país, por atenderem a setores sociais específicos, com pouca atenção às interdependências e às complementaridades das ações. $O$ seguimento da agricultura que não se encontra inserido nas principais cadeias produtivas ou complexos agroindustriais voltados à exportação foi negligenciado historicamente na formulação de políticas agrícolas. Durante praticamente todo século XX, a orientação do Estado foi para conduzir à modernização de sua estrutura de produção agropecuária, tendo como foco o aumento da produtividade a partir da incorporação de avanços tecnológicos, e como público-alvo a empresa rural capitalizável, caracterizada por grandes extensões de terra e acesso garantido a abundantes subsídios fiscais e creditícios (FERREIRA, 2002).

Somente em meados dos anos 1990, com o surgimento do Programa Nacional de Fortalecimento da Agricultura Familiar (PRONAF), os produtores familiares rurais puderam dispor de um programa governamental voltado para favorecer-lhes de fato. O PRONAF foi criado em 1996 pelo governo federal, por meio do Decreto $n^{\circ}$ 1.946. Seu intuito principal é garantir os recursos para o apoio às atividades produtivas do segmento da agricultura familiar no Brasil. Dessa forma, o PRONAF veio para satisfazer, por um lado, questões importantes para a dinâmica da agricultura familiar e sua relação com as economias dos territórios em que estão 
inseridas, e por outro, dada sua execução pelo sistema bancário, incorporar na dinâmica do capitalismo de mercado um enorme contingente de agricultores com baixa capacidade de investimento produtivo. Para tanto, foi organizado em três linhas distintas: PRONAF Crédito, a principal em termos de volume de recursos; PRONAF Infraestrutura e Serviços Municipais, que a partir de 2003 passou a ser discutida e deliberada em âmbito territorial; e o PRONAF Capacitação, que perdeu sua importância atualmente e por isso não será debatido neste trabalho.

O PRONAF avançou ao longo dos anos no sentido de incorporar, gradativamente, a diversidade de atores que compreendem o universo da agricultura familiar no Brasil. A partir de 1999, passaram a ocorrer modificações importantes no desenho institucional do programa, sobretudo no que se refere à concessão de créditos. Com base em estudos da FAO/INCRA (1994), optou-se por segmentar os agricultores beneficiários em grupos distintos. A Resolução no 2.629 (10/08/1999) definiu quatro grupos (A, B, C, e D) de agricultores familiares com base principalmente na renda bruta anual. Essa adequação propiciou que as regras de financiamento atendessem melhor à "realidade de cada segmento social, sendo que os encargos financeiros e os rebates (descontos) visam auxiliar mais as parcelas com menores faixas de renda e em maiores dificuldades produtivas". Em 2004 foi incorporado um novo grupo (grupo E), atendendo à pressão de grupos de agricultores mais capitalizados. Além desses grupos, novas linhas especiais de financiamento foram criadas para mulheres, jovens, cooperativas, agroindústrias, entre outras, com condições diferenciadas para o acesso ao crédito (SILVA, 2011).

Em 2004, incluiu-se no Plano Plurianual 2004-2007 o Programa de Desenvolvimento Sustentável de Territórios Rurais (PRONAT), sob a responsabilidade do MDA. O PRONAT, centrado na reativação das economias locais e na gestão sustentável dos recursos naturais, foi concebido para ser implementado no longo prazo e alcançar todos os espaços rurais do Brasil, especialmente aqueles cujos perfis apresentem características de estagnação econômica, problemas sociais e riscos ambientais, com ponderável presença de agricultores familiares. Para alcançar suas principais metas, um dos objetivos apontados por Silva (2014) era articular ações conjuntas com outros órgãos da administração federal, estadual e municipal, bem como da sociedade civil em geral.

Atualmente, o MDA atua em 164 territórios rurais, os quais compreendem um total de 2.392 municípios, em todos os estados brasileiros. Em Minas Gerais existem 12 territórios rurais homologados pelo MDA, e entre eles está o Território Vale do Mucuri, objeto deste estudo. Para fortalecer e garantir o processo de gestão social dos territórios rurais, em cada um deles são constituídos os Conselhos de Desenvolvimento Territorial Rural Sustentável (CODETER), formados de maneira paritária entre representantes do poder público local e sociedade civil. Esses espaços constituem-se como as instâncias maiores de deliberação no território no que diz respeito a políticas de desenvolvimento rural. De acordo com Delgado e Leite (2011), entre as principais atribuições desses órgãos colegiados estão: i) divulgar as ações de desenvolvimento territorial; ii) identificar demandas locais para serem priorizadas pelos órgãos gestores competentes, de acordo com critérios existentes iii) promover a interação entre gestores públicos e conselhos setoriais; iv) contribuir com sugestões para qualificação e integração de ações públicas e privadas no território; v) sistematizar as contribuições para o Plano Territorial de Desenvolvimento Rural Sustentável (PTDRS); e vi) exercer o controle social do programa. Nesse sentido, os autores afirmaram que: 
[...] a participação social garantiria a vigência dos princípios que marcariam a diferença entre a "velha" experiência de planejamento do desenvolvimento rural (muito em voga nas décadas de 1970 e 1980, incentivada pelos programas financiados por agências multilaterais) e a recente iniciativa de planejamento e desenvolvimento territorial (p. 437).

Com a reestruturação do MDA e a definição de diferentes territórios rurais para o planejamento das políticas públicas de desenvolvimento rural no Brasil, o PRONAF Infraestrutura deixou de estar diretamente ligado à estratégia municipal, como era no início, para ser um dos principais instrumentos institucionais e orçamentários para a nova estratégia de desenvolvimento territorial de regiões rurais no Brasil (SILVA, 2012).

Paralelamente ao PRONAF, outras políticas públicas surgiram como incentivo à produção familiar agrícola. Uma delas foi a Política Nacional de Assistência Técnica e Extensão Rural (PNATER), lançada em 2003 com o objetivo de reestruturar o sistema de assistência técnica no Brasil, tendo como foco as propriedades rurais familiares. Outro programa, que surgiu no interior do Programa Fome Zero do governo federal em 2003, é o Programa de Aquisição de Alimentos (PAA), que permite a compra pública de produtos de agricultores familiares, a preços estabelecidos pela CONAB, para doação, merenda escolar ou formação de estoques, e objetiva aliar a necessidade de geração de oportunidades de trabalho e renda aos trabalhadores rurais e garantia da segurança alimentar às populações necessitadas no Brasil (DÁVILA; SILVA, 2012).

O lançamento desses novos programas e o crescimento contínuo ao longo dos anos dos recursos destinados, que culminou em uma abrangência maior em termos do número de municípios e de famílias envolvidas, permitiu o surgimento de um novo cenário para a agricultura familiar no Brasil. Por outro lado, a criação de novos espaços de participação dos agricultores familiares, por meio de suas organizações sociais representativas, e o reconhecimento de sua importância nas dinâmicas econômicas e políticas locais, possibilitaram outras oportunidades de interação entre atores sociais com distintos interesses para uma melhor incidência das políticas públicas em contextos territoriais diferenciados. No caso do PRONAF, com suas diferentes linhas de ação e um complexo arranjo institucional, a importância dessas interações é algo que pode ser bem visível a partir de uma análise territorial. Nesse sentido, as seções seguintes apresentam as características identificadas a partir da incidência do PRONAF no Território Vale do Mucuri.

\section{O TERRITÓRIO VALE DO MUCURI}

O Território Vale do Mucuri (TVM) foi constituído no âmbito da nova estratégia do PRONAF Infraestrutura, elaborada a partir de uma abordagem territorial para os investimentos públicos, como visto anteriormente. Inicialmente, os principais articuladores para a constituição do território e sua inserção na política territorial do MDA foram o Instituto de Desenvolvimento do Norte e Nordeste de Minas (IDENE) e a Associação dos Municípios do Vale do Mucuri (AMUC). Outras organizações foram se integrando ao processo, como a Empresa de Assistência Técnica e Extensão Rural do Estado de Minas Gerais (EMATER), os sindicatos de trabalhadores rurais e os movimentos sociais da região. 
Nesse contexto, o TVM foi homologado pelo MDA em nove de outubro de 2003, composto por 27 municípios, quais sejam: Águas Formosas, Ataléia, Bertópolis, Campanário, Caraí, Carlos Chagas, Catuji, Crisólita, Franciscópolis, Frei Gaspar, Fronteira dos Vales, Itaipé, Itambacuri, Ladainha, Machacalis, Malacacheta, Nanuque, Novo Oriente de Minas, Ouro Verde de Minas, Pavão, Pescador, Poté, Santa Helena de Minas, Serra dos Aimorés, Setubinha, Teófilo Otoni e Umburatiba. O território localiza-se na Macrorregião Jequitinhonha/Mucuri, a nordeste de Belo Horizonte, como mostra a figura 2 a seguir. Está inserido nas seguintes Bacias Hidrográficas: Rio Doce, São Mateus, Itanhém, Jequitinhonha, Peruípe, Itaúnas e Rio Mucuri, sendo essa última, a bacia de maior importância, pois abrange $59 \%$ dos municípios no território. A área ocupada pelo território corresponde a uma extensão de $23.498,20 \mathrm{~km}^{2}$, ou seja, $4 \%$ da área total de Minas Gerais (MDA, 2007).

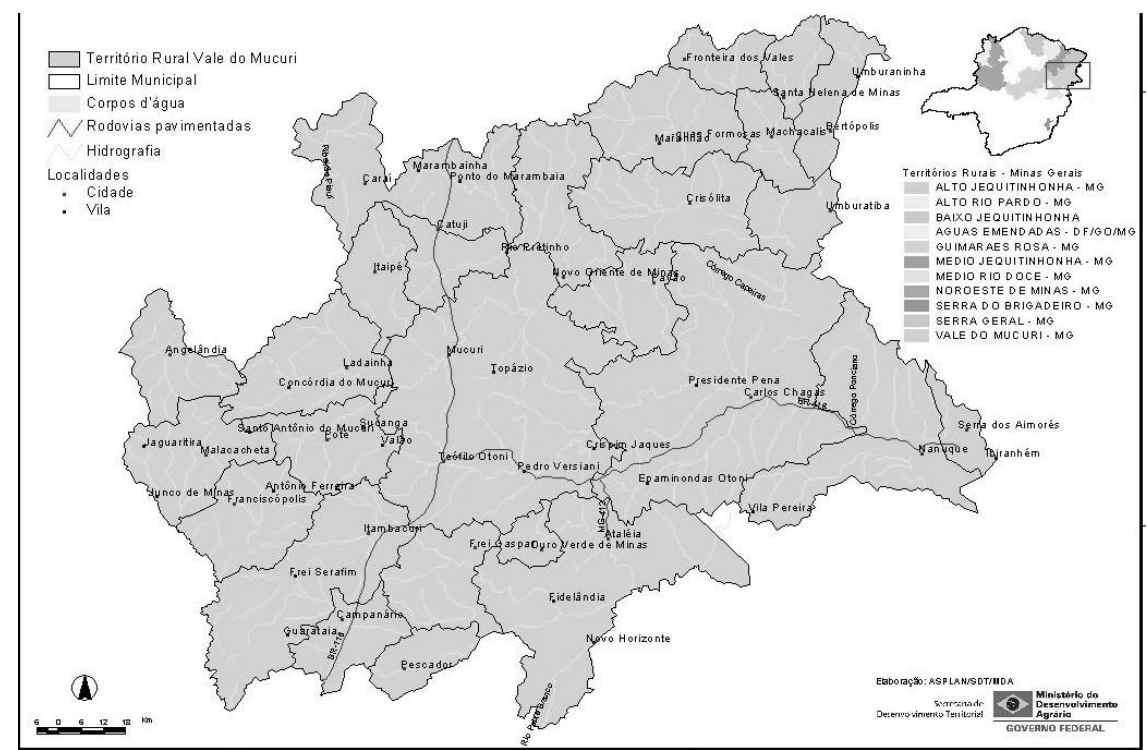

Figura 2 - Mapa do Território Vale do Mucuri/MG

Fonte: MDA (2007)

A população do TVM é de aproximadamente 431.840 habitantes $(2,4 \%$ do total do estado), sendo $62,8 \%$ da população vivendo na área urbana e $37,2 \%$ na área rural, segundo dados do Censo Populacional de 2010. O município de Teófilo Otoni é o de maior população, apresentando $30 \%$ da população do território, e é também o de maior extensão. Em termos de indicadores sociais, a média do Índice de Desenvolvimento Humano Municipal (IDH-M) ${ }^{4}$ no território é igual a 0,675, ficando o componente longevidade com média de 0,686, educação com 0,741 e renda com 0,595 . Os indicadores de desenvolvimento humano mostram também que nenhum dos 27 municípios possui IDH maior que o estadual e nacional.

\footnotetext{
${ }^{4} \mathrm{O} I \mathrm{IDH}$ é um indicador que a partir da conjugação das variáveis: educação, longevidade e renda. Calcula-se a capacidade de desenvolvimento de uma sociedade, variando de 0 a 1 , quanto mais próximo de 1 , maior o grau de desenvolvimento humano da sociedade. De acordo com o Programa das Nações Unidas para o Desenvolvimento (PNUD) com este indicador pode-se enforcar os problemas de desenvolvimento numa perspectiva mais humana, social e sustentável.
} 
Com relação à economia do território, a primeira informação que chama a atenção é a pequena renda gerada pelos municípios. O território responde por apenas $1,3 \%$ da renda total gerada em Minas Gerais. Isso faz com que uma parcela grande das famílias, sobretudo no meio rural, dependam de programas sociais de transferência de renda (aposentadoria, Bolsa Família, etc.) para a composição da renda familiar. A integração na economia estadual e nacional ocorre por meio da especialização no comércio de pedras semipreciosas e na exportação de produtos agropecuários de baixo valor agregado, especialmente da pecuária leiteira. De modo geral, predomina no território um baixo dinamismo econômico e a escassez das oportunidades de ocupação e geração de renda, sendo as transferências e os repasses governamentais uma importante fonte de receita dos municípios que o compõem (SCHROEDER, 2007).

A maior parte da área rural dos municípios do território refere-se a pastagens, seguido de matas e florestas e áreas em descanso. A produção com maior área ocupada é a pecuária, que representa $77 \%$ do total. O segundo setor com maior área ocupada é a produção mista, representando $11 \%$ da área total ocupada do território. Cerca de $70 \%$ do Valor Anual da Produção (VAP) no território é proveniente da produção animal, outros $26,2 \%$ decorrem dos cultivos vegetais (MDA, 2007).

A agricultura familiar no território é bem representativa no TVM, envolvendo cerca de 25 mil famílias em 656 comunidades rurais do território. A diversidade étnica, cultural e de organização social da agricultura familiar inclui comunidades tradicionais originadas por indígenas, afrodescendentes, migrantes e imigrantes. A multiplicidade de práticas agrícolas notadas nos sistemas familiares do TVM retrata as formas de viver, organizar e conhecer das populações identificadas com o rural (UFVJM, 2010).

Em suma, as famílias de agricultores combinam em suas propriedades: 1) a produção de alimentos, especialmente mandioca, milho e feijão (lavouras com volume de produção e nível de produtividade baixos e uso pouco intenso de forca mecânica e insumos industriais, a exceção da olericultura), além da cafeicultura em alguns dos municípios do território; 2) a criação de pequenos e grandes animais (pecuária de corte e leite, aves e suínos), que serve como forma de geração de renda (com a comercialização dos vários subprodutos), de poupança familiar (que pode ser revertida em recursos monetários) e como fonte de alimentos (ovos, carne, leite e derivados); 3) o beneficiamento de derivados da cana, leite e mandioca; 4) a produção de mudas floríferas e frutíferas e de hortaliças e condimentos para consumo em alguns dos municípios do território; e 5) a obtenção de rendas monetárias, por intermédio de uma inserção mercantil reduzida (comercialização dos excedentes na feira, no comercio local ou para laticínios e atravessadores, especialmente), das migrações sazonais (especialmente para o trabalho em monoculturas no sul de Minas Gerais, interior de São Paulo e norte do Espírito Santo), das diárias da venda da forca de trabalho, da aposentadoria e das políticas de assistência social (SCHROEDER, 2007).

Apesar da predominância da agricultura familiar no meio rural do TVM, as propriedades que compõem esse segmento enfrentam um fator fortemente limitante para seu desenvolvimento, que é a concentração de terras na região. Segundo dados do Censo Agropecuário (IBGE, 2006), no TVM a agricultura familiar possui 13.878 estabelecimentos rurais, totalizando uma área de 296.387 hectares; enquanto que a agricultura patronal possui 3.679 estabelecimentos, e uma área disponível de 923.204 hectares. Ou seja, o tamanho médio dos estabelecimentos de agricultura familiar é de 21,4 hectares, e da agricultura patronal, 250,9 hectares, o que equivale a um tamanho médio mais de dez vezes maior por parte da segunda. 
Tal situação se agrava ainda mais quando se observa que $55,7 \%$ das propriedades familiares possuem menos de 10 hectares. Outro ponto que chama a atenção é que $34 \%$ das famílias moravam em terras cedidas por parentes, o que demonstra o parcelamento das propriedades ao longo do tempo, fato que acelera o processo de minifundiarização na região.

Segundo relatório da UFVJM (2010), as comunidades de agricultura familiar estão literalmente estranguladas nas áreas que não são de interesse dos fazendeiros, geralmente as propriedades se encontram nas áreas mais altas, menos férteis, que apresentam maior dificuldade para o cultivo. O caráter perverso dessa concentração reside no fato de que o acesso a terra é um dos primeiros requisitos necessários para a garantia de sobrevivência e permanência das pessoas no campo, de modo que o tamanho da propriedade constitui-se num elemento fundamental para a qualidade de vida no meio rural. A instabilidade causada pela baixa quantidade de terras contribui para uma maior dependência do mercado externo, aumentando os índices de migração nas comunidades.

Além da questão da forte concentração fundiária, os municípios do TVM também sofrem de sérios problemas advindos do modelo de desenvolvimento adotado em toda a região ao longo dos anos. Por todo o território, observa-se uma intensa degradação dos solos, desmatamentos dos remanescentes da Mata Atlântica, queimadas e assoreamento de córregos e rios. O avanço de grandes maciços florestais de eucaliptos, a partir da expansão das atividades das empresas de papel e celulose atuantes nos estados do Espírito Santo e da Bahia, também decorre em conflitos ambientais e sociais na região, dada a pressão que exerce sobre os ecossistemas regionais (especialmente, sobre as nascentes de rios) e as unidades produtivas familiares (inclusive, com o arrendamento ou a aquisição das terras dessas unidades).

A conservação da água foi apontada como um dos eixos prioritários na elaboração do Plano de Territorial Desenvolvimento Rural Sustentável (PTDRS) do TVM. De acordo com os agricultores locais, a quantidade de água disponível vem se reduzindo gradualmente ao longo dos anos, sua qualidade tem se deteriorado, e muitas pessoas são ainda privadas ou tem acesso dificultado a fontes de água potável (UFVJM, 2010). Por todas essas questões, a temática da sustentabilidade ambiental passou a ser um dos elementos fundamentais para uma estratégia de desenvolvimento territorial no TVM.

Após essa breve caracterização geográfica e socioeconômica do território em análise, a próxima seção apresenta um estudo sobre o ambiente institucional envolvido na operacionalização das políticas públicas de desenvolvimento rural no TVM. Buscou-se saber quais são os atores sociais envolvidos e seus papéis, quais as principais políticas em curso e quais os aspectos da incidência dessas políticas públicas no território analisado, levando-se em conta suas múltiplas dimensões.

\section{AMBIENTE INSTITUCIONAL E OPERACIONALIZAÇ̃̃O DAS POLÍTICAS PÚBLICAS DE DESENVOLVIMENTO RURAL NO VALE DO MUCURI}

Como já destacado anteriormente, o PRONAF é a principal ação governamental de apoio e fomento às atividades produtivas dos agricultores familiares no Brasil. No caso específico do PRONAF Crédito e sua dinâmica no TVM, as etapas para seu acesso podem ser descritas resumidamente em três pontos principais: i) o fornecimento da Declaração de Aptidão ao PRONAF (DAP), por intermédio da Empresa de Assistência Técnica e Extensão Rural (EMATER) e/ou do Sindicato de Trabalhadores Rurais (STR); ii) a elaboração do projeto de 
crédito pela EMATER, às vezes com apoio do técnico da prefeitura, quando há; e iii) a avaliação do crédito pelos bancos, conforme seus critérios.

É importante ressaltar que a abrangência do PRONAF junto à agricultura familiar vem aumentando gradativamente no TVM. Conforme demonstrado na figura 2 , houve um salto significativo ao longo da primeira década dos anos 2000 . O valor total do crédito aplicado nesse período chegou próximo a $\mathrm{R} \$ 93$ milhões. Percebe-se que os anos de 2006 e 2007 apresentaram os maiores valores destinados à região, superando a marca dos $\mathrm{R} \$ 20$ milhões. Mesmo com esses resultados, o programa ainda tem bastante espaço para crescer nos municípios do TVM, uma vez que, de acordo com estimativas locais, até 2009 apenas 53\% dos agricultores familiares haviam acessado essa política (UFVJM, 2010).

Em 2008, observou-se uma forte retração do crédito, embora tenha aumentado o número de contratos em relação ao ano anterior, ou seja, ocorreu uma redução do valor médio dos contratos. A explicação para esse fato é que nesse ano houve uma queda tanto no número de contratos, como também no valor médio financiado para os agricultores familiares mais estruturados (grupos D e E), com maior capacidade de endividamento, que tiveram sua importância relativa em termos de financiamento mais destacada a partir de 2004, quando o grupo $E$ foi criado (SILVA, 2008). Para compensar um pouco essa queda, em 2008 houve um aumento do número de contratos do PRONAF B, que apresentava queda desde 2006, quando havia alcançado seu pico. No entanto, como o limite de financiamento para esse grupo é pequeno, o ano de 2008 terminou com um menor volume de recursos financiado no TVM, com relação aos dois anos anteriores.

Vale ressaltar que o PRONAF $\mathrm{B}$ tem uma importância muito grande no TVM, já que, das quase 25 mil propriedades familiares rurais no conjunto de seus municípios, 64\% se enquadram no grupo B. Em todo o período (2000 a 2008), a participação dessa categoria no total de contratos no TVM foi de $77 \%$, mas em termos de volume de recursos representou apenas 36\%. Tais números, por si só, já denotam a situação de fragilidade econômica que caracteriza a agricultura familiar no território, justificando a necessidade de uma atuação integrada no sentido de potencializar os investimentos de políticas públicas voltadas a esse público. De acordo com relatório da UFVJM (2010), os arranjos institucionais formados no nível local, baseados em parcerias entre poder público municipal, sindicato de trabalhadores rurais e técnicos do escritório local da EMATER, foram fundamentais na ampliação do acesso de agricultores ao PRONAF B nos municípios do TVM, como apresentado na figura seguinte. 


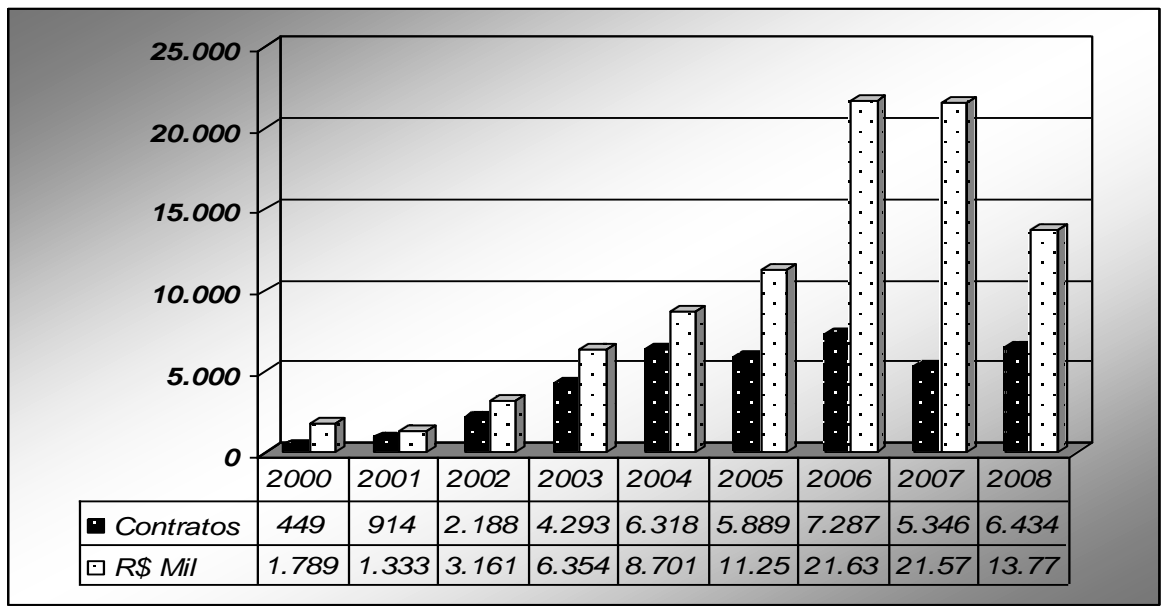

Figura 3 - Evolução do Pronaf no TVM (2000 A 2008)

Fonte: Banco de dados do MDA

Para além do crédito, desde o início da operacionalização do PRONAF, uma série de outras ações complementares ou paralelas de apoio à agricultura familiar vem marcando a história recente das políticas públicas de desenvolvimento rural no território. Além das ações propriamente ditas, um conjunto amplo de instituições e suas respectivas organizações nos municípios vêm sendo envolvido para compor o arranjo institucional que permeia a operacionalização dessas ações governamentais.

No caso das organizações do poder público, são envolvidas as três esferas administrativas. No âmbito federal, pode-se citar ministérios e autarquias importantes com ações incidindo sobre o TVM. O Ministério do Desenvolvimento Agrário (MDA) é o principal deles, pois define as diretrizes operacionais do PRONAF, tanto no caso das operações de crédito como para os recursos de infraestrutura, que são acessados por meio de projetos definidos no CODETER/TVM, o âmbito o PRONAT ${ }^{5}$. O Instituto Nacional de Colonização e Reforma Agrária (INCRA), que também faz parte da estrutura do MDA, coordena as ações de reforma agrária e regularização fundiária. Outros ministérios com programas importantes são: Ministério da Integração Nacional (Programa de Desenvolvimento Integrado da Mesorregião dos Mesovales Jequitinhonha e Mucuri), e o Ministério das Minas e Energia (Programa Luz para Todos). A partir de 2007, o TVM foi incluído no Programa Territórios da Cidadania ${ }^{6}$, que foi uma estratégia do governo federal de articular as ações de políticas públicas de diferentes instâncias de governo em regiões com alto índice de pobreza e carências sociais.

Já em relação ao poder público municipal, as prefeituras possuem papel fundamental na mediação desses processos, sobretudo após o processo de

\footnotetext{
${ }^{5}$ Sobre o processo de elaboração e encaminhamento dos projetos prioritários nos territórios rurais inseridos no PRONAT, ver Silva (2014).

${ }^{6}$ O Programa Territórios da Cidadania foi lançado no dia 25 de fevereiro de 2008. É administrado pelo governo federal, por intermédio da Casa Civil, e envolve outros 24 órgãos públicos, entre ministérios e autarquias diferentes (SILVA, 2012).
} 
descentralização administrativa das políticas sociais a partir de meados dos anos 1990 no Brasil. Nos municípios em que as prefeituras são mais atuantes e estabelecem, em alguma medida, relações diferenciadas com o sindicato de trabalhadores rurais e o escritório local da EMATER, o resultado obtido é melhor (SCHROEDER, 2007). Por isso, no acesso ao crédito, o posicionamento das prefeituras em relação aos agricultores familiares é fundamental para sensibilizar os agentes financeiros para à importância desse programa para a economia local. Além disso, as prefeituras são responsáveis pelo estabelecimento de convênios para a manutenção do escritório municipal da EMATER para a oferta de serviços de assistência técnica aos agricultores locais. Nesses convênios, as prefeituras se encarregam de fornecer o apoio material para a manutenção dos trabalhos e, em alguns casos, ela própria disponibiliza mais um técnico para disposição do escritório local e assim melhorar a prestação de serviços.

Uma atuação mais contundente por parte das prefeituras para a captação de recursos oriundos das políticas públicas de desenvolvimento rural, além de propiciar melhorias diretas para a vida das famílias beneficiadas, contribui também para a dinâmica econômica dos seus municípios. Silva (2008) diagnosticou que os recursos dessas políticas (em especial os créditos do PRONAF), entram como uma injeção de liquidez na economia desses municípios e acarretam em impacto positivo no Produto Interno Bruto (PIB) total, setorial e per capita, na renda média das famílias, na geração de emprego e na arrecadação de impostos nos municípios, argumentos importantes para convencer os prefeitos de municípios com forte presença de agricultores familiares a qualificarem suas intervenções nesses programas. A ausência da prefeitura nesse processo de mediação acaba dificultando bastante a ação da EMATER e das organizações de representação dos trabalhadores rurais.

A viabilização dos trabalhos da EMATER por parte do poder público é importante também para a garantia da assistência técnica aos empreendimentos comunitários no território - como no caso das "casas de farinha" (unidades de beneficiamento da mandioca) -, muitos deles constituídos sob a forma de associação de agricultores. As lideranças dessas associações desempenham papel importante nos arranjos constituídos para a mediação das políticas públicas com o apoio de sindicatos e outros parceiros.

No entanto, a realidade dos serviços de assistência técnica no TVM ainda apresenta-se bem aquém do requerido pelos agricultores e suas organizações, devido às dificuldades estruturais para sua oferta. São ao todo 85 técnicos distribuídos nos 27 municípios, para atender os quase 25 mil agricultores familiares, o que representa, em média, três técnicos por município, ou um técnico para cada 294 agricultores, enquanto a média recomendada pelo próprio MDA é de um técnico para cada 100 agricultores (MDA, 2007). Essa deficiência em termos de oferta de assistência técnica compromete bastante a efetividade de programas de apoio à agricultura familiar no território. No caso do PRONAF, o papel do técnico é fundamental em várias das etapas para o acesso ao crédito, por exemplo: desde a divulgação do programa, em consonância com a atuação do STR, passando pelo enquadramento da renda do agricultor para a emissão da DAP, até a elaboração do projeto ou da proposta - fundamental na relação com o agente financeiro - e o acompanhamento técnico posterior. Além da necessidade de um quadro técnico maior e mais qualificado, ações de fortalecimento do capital social no território, como destacou Abramovay (2000), também são importantes para potencializar a capacidade de monitoramento e a apropriação das políticas por parte dos atores locais. 
A questão fundiária também é central no território. Em seus municípios, há um grande contingente de trabalhadores rurais que trabalham em alguma forma de comodato ou parceria por não disporem de terra própria para o cultivo. Além disso, há uma tendência à minifundiarização da área ocupada pelos estabelecimentos familiares via mecanismo de fracionamento das propriedades.

A ineficiência na regularização fundiária e a tendência à minifundiarização explicitam dois problemas para os agricultores do TVM. Um deles é que, quanto menor a média dos estabelecimentos rurais, menor a capacidade de geração de renda digna para a reprodução familiar, já que diminui o leque de atividades a serem exercidas, o que acaba por aumentar a dependência das famílias a rendas externas à propriedade e a transferências governamentais. Outro problema refere-se ao entrave no acesso a linhas de créditos para a atividade produtiva, devido à falta de garantias materiais por parte dos agricultores aos agentes financeiros.

De acordo com Schroeder (2007), as transformações econômicas na região e a apropriação privada das terras restantes impedem o fracionamento de outras porções de terra no território. Além disso, as especificidades da ocupação histórica das terras (a pecuária extensiva ainda é uma das mais importantes atividades da região, além da monocultura do café), do quadro natural (relevo acidentado, vegetação e clima diversificados) e as características dos sistemas produtivos dos agricultores do Vale do Mucuri, que têm relação direta com aquelas especificidades, determinaram certo grau de impermeabilidade da região às políticas que não apresentam flexibilidade suficiente para serem adaptadas a essas especificidades.

Segundo dados do território, existem atualmente 15 projetos de assentamento em seus municípios, sendo três do INCRA, cinco do governo estadual, e nove provenientes do antigo Programa Banco da Terra ${ }^{7}$. Nesses projetos estão assentadas 845 famílias. Os municípios de Santa Helena de Minas e Teófilo Otoni respondem por cerca de 3/4 do total, com 420 e 205 famílias respectivamente. Destaca-se também no território a presença de famílias em comunidades de pescadores artesanais (348 famílias no total), quilombolas (373 famílias) e indígenas (193 famílias) ${ }^{8}$, grupos que também estão incluídos no rol de beneficiários das políticas públicas para a agricultura familiar. Enquanto os assentados de reforma agrária possuem ao menos a estrutura e ações do INCRA para auxiliá-los, por mais precária que venha sendo essa relação, como relatam alguns assentados, as demais comunidades encontram-se em situação mais drástica, devido a sua dificuldade de representação e organização para, principalmente, estabelecer sua relação com o poder público (UFVJM, 2010).

A situação de fragilidade em termos de direitos de propriedade dessas famílias, juntamente com a extrema concentração de terras que caracteriza o território, fazem com que a questão fundiária seja um entrave no acesso ao credito, pela falta de terras para o desenvolvimento dos projetos de investimento (o tamanho da área disponível para o agricultor define o montante do projeto) ou pelas dificuldades em comprovar a posse em caso de credito pleiteado por agricultores dos grupos $\mathrm{C}$, D e E, ainda que as normas do PRONAF indiquem que o acesso possa ocorrer sem a exigência de garantias materiais e a agricultores que detenham a posse pacifica do imóvel rural.

\footnotetext{
${ }^{7}$ Implantado no Brasil em 1997, na gestão do presidente FHC, com o apoio e influência do Banco Mundial. Trazia em seu âmbito uma proposta de "reforma agrária de mercado".

8 Os indígenas são predominantemente da população Maxacali, que possui demarcação de território constado na Fundação Nacional do Índio (FUNAI), nos municípios de Ladainha (Aldeia Verde), Teófilo Otoni (Aldeia Cachoeirinha), Bertópolis (Aldeia Pradinho) e Santa Helena (Aldeia Água Boa). Ocorrem muitos conflitos entre o povo Maxacali e os fazendeiros encontrados nos arredores do território (UFVJM, 2010).
} 
Partindo para a análise da atuação das organizações da sociedade civil envolvidas na operacionalização do PRONAF e demais políticas de desenvolvimento rural, a participação dos Sindicatos de Trabalhadores Rurais (STR) possui papel fundamental, principalmente na parte da mobilização dos agricultores e na divulgação das normas, responsabilidades e vantagens do programa nas comunidades rurais. Outra função dos STRs é de negociar junto às instâncias dos governos municipal, estadual e federal, condições mais favoráveis para sua base social em relação ao acesso aos créditos do PRONAF.

No entanto, os STRs no TVM enfrentam, em sua maioria, fortes dificuldades em exercer seu papel de mediação das políticas públicas de fortalecimento da agricultura familiar no território. As organizações representativas dos agricultores padecem de estrutura reduzida quanto ao apoio técnico e financeiro, o que interfere na construção de "habilidades sociais" que as credenciem a atuarem na articulação institucional de um processo que envolve tantos atores externos com interesses distintos. Segundo Fligstein (2001), o conceito de habilidades sociais enfatiza o papel de atores estratégicos socialmente e suas habilidades para liderar a instauração de redes ou grupos criativos que possuem certa identidade com vistas à ação coletiva.

Com isso, os STRs têm buscado consolidar suas parcerias com organismos mais próximos (sobretudo conselhos, prefeituras, EMATER e associações comunitárias), com vistas a formar uma rede local para garantir um arranjo organizacional mais sólido, que os permita alcançar um melhor fluxo de informações, maior capacidade de acesso a recursos e maior velocidade e capacidade de ação. Além dessas articulações, as ações da Igreja Católica (principalmente via Comissão Pastoral da Terra) e de ONGs também permitem e fortalecem a expansão da atividade sindical. No entanto, os STRs precisam se relacionar com atores sociais diferentes para construir formas de cooperação que qualifiquem sua atuação no campo da mediação de políticas públicas (SCHROEDER, 2007).

Já a função dos agentes financeiros na operacionalização do PRONAF está ligada diretamente à gestão dos recursos do programa. São eles que realizam as operações de crédito junto aos agricultores a partir das deliberações do governo federal. A cada novo ano agrícola, novas medidas são desenvolvidas no intuito de reduzir a burocracia e facilitar o acesso dos agricultores aos créditos do PRONAF, sobretudo aqueles do grupo $\mathrm{B}$, que geralmente possuem baixos índices de escolaridade formal, maior dificuldade para a comprovação da posse de sua propriedade agrícola e, até, mesmo, inexistência de documentação pessoal.

Os principais agentes bancários na operacionalização do PRONAF no TVM são o Banco do Nordeste (BNB) e o Banco do Brasil (BB), que dependem muito do estabelecimento de parcerias para expandirem sua atuação e atendimento aos agricultores. Essas parcerias permitem a redução de custos de transação envolvidos nas operações e contribuem para o menor distanciamento social na relação entre agricultores familiares e agentes financeiros, com as organizações parceiras participando da mediação entre ofertantes e tomadores de crédito. O BB aumentou sua participação no PRONAF principalmente a partir de 2004, quando começou a operar os contratos do PRONAF B na região. No caso do BNB, embora tenha reconhecida atuação nas operações, ainda possui uma pequena presença no território, contando com apenas uma agência, com sede em Teófilo Otoni, para atender os 27 municípios. Esse fato, por si só, já designa uma gama de limites para a atuação do BNB na operacionalização do PRONAF no território: volume muito grande de projetos submetidos em relação à capacidade instalada da agência; lentidão no processamento das operações; distância física entre a agência 
concedente e os agricultores demandantes das operações de crédito; e dificuldade de atuação das organizações locais na mediação da política.

Para resolver parte desses problemas e melhorar 0 atendimento nos bancos, algumas inovações foram criadas. O BNB buscou estabelecer pontos de apoio e atendimento via parcerias com prefeituras, STR e EMATER. Já o BB criou o sistema chamado Canal Facilitador de Crédito (CFC), no qual terceiriza a operacionalização do custeio dos grupos $\mathrm{C}$ e $\mathrm{D}$ e do investimento do grupo B. Nesse sistema, o técnico apenas assina as propostas de crédito. Mesmo assim, ao tratar sobre esse ponto, Schroeder (2007) apontou algumas dificuldades na concretização dessas parcerias:

[...] poucos municípios do território têm operado o sistema, justamente porque para o funcionamento do CFC é preciso ter, pelo menos, um computador on line (quando o acesso a internet ainda é restrito em alguns lugares) e um funcionário capacitado e dedicado ao atendimento dos agricultores, ao preenchimento da proposta e às devidas consultas cadastrais, uma demanda que acaba sendo grande para a pequena estrutura que têm prefeituras e sindicatos nos municípios rurais. Os dirigentes sindicais relatam sempre a mesma coisa (p. 41).

Passando, por fim, à análise dos arranjos envolvidos na inserção mercantil dos produtos de agricultura familiar no território, nota-se a existência de muitos entraves ao acesso mais estável a mercados. Os principais postos de comercialização dos produtos da agricultura familiar são as feiras livres municipais, os estabelecimentos de comércio local e alguns entrepostos varejistas de cidades maiores (como Teófilo Otoni e Governador Valadares), além da ação de "atravessadores" e, no caso do leite, dos laticínios. A ausência de uma infraestrutura (pública ou privada) adequada para beneficiamento e comercialização dos produtos, faz dos agricultores dos municípios do território mais dependentes da ação dos atravessadores (SCHROEDER, 2007).

Uma alternativa interessante para aumentar os canais de comercialização é garantia da compra de alimentos e demais produtos de agricultores familiares para satisfazer a demanda de mercados institucionais. É com essa finalidade que o Governo Federal lançou o Programa de Aquisição de Alimentos da Agricultura Familiar (PAA), instituído pela Lei 10.696 de 2003, que visa adquirir produtos in natura ou beneficiados para mercados institucionais, como a compra de alimentos para merenda escolar. No entanto, até então o PAA apresentou um alcance modesto no TVM, restringindo-se, até 2009, aos municípios de Teófilo Otoni, Frei Gaspar e Pavão. Entre relatos de representantes da CONAB, da EMATER e dos agricultores familiares, pode-se citar como fatores limitantes deste programa no território: circulação de informação restrita; exigências de formalização das organizações; inexistência de contadores em alguns dos municípios para a emissão dos documentos fiscais necessários para a prestação de contas; ausência de fiscalização sanitária dos produtos de origem animal (não existem serviços de inspeção municipal); dificuldades de transporte dos produtos; restrições operacionais que enfrentam as prefeituras municipais; entre outros, que na verdade resultam de entraves estruturais próprios do processo de desenvolvimento histórico da região.

Mesmo com todas essas dificuldades, pôde-se notar a partir das participações em reuniões do CODETER/TVM e de conversas informais com seus representantes uma grande vontade das organizações locais em empreender os esforços necessários para construir um ambiente institucional mais favorável, com 
vistas a potencializar os resultados dessas políticas públicas em seu território e com a agricultura familiar protagonizando esse processo. Ademais, para economias de baixa dinamicidade, como é o caso dos municípios do Vale do Mucuri, não se pode desconsiderar o papel dessas políticas públicas e seus recursos monetários como uma importante injeção de liquidez nas economias locais.

\section{CONSIDERAÇÕES FINAIS}

Os elementos analisados neste trabalho evidenciam a existência de grandes desafios a serem vencidos no TVM para potencializar e qualificar o acesso aos créditos do PRONAF e também a outras políticas públicas voltadas ao segmento sócio-produtivo da agricultura familiar, tais como: assistência técnica, beneficiamento e comercialização da produção, infraestrutura e reforma agrária. Esses desafios podem ser melhor enfrentados com o fortalecimento das estratégias dos atores locais e com a consolidação dos arranjos institucionais que transcendem o plano municipal para o nível territorial, ampliando o debate e fortalecendo uma estrutura de rede de interlocução entre agentes do meio público e privado, inclusive contando com o envolvimento de outros setores não exclusivos do meio rural.

Todas as dificuldades existentes nos municípios do Vale do Mucuri não são muito diferentes das encontradas em outros territórios rurais brasileiros, e elas refletem diretamente na organização social do território e sua baixa permeabilidade frente às demandas sociais locais. Porém, as próprias organizações locais apontaram que as conquistas até agora alcançadas referem-se às mobilizações e iniciativas já em curso, e que esse processo propicia também um aprendizado importante para a geração das competências locais e habilidades sociais exigidas em cada programa ou ação.

Isso pode ser observado pelas análises referentes à evolução do PRONAF, que apontam uma ampliação considerável nos municípios do território Vale do Mucuri tanto em termos de recursos como em termos de número de contratos no período. Entre os fatores diagnosticados neste trabalho que podem explicar esse resultado estão: aumento do volume de recursos e inovações nas regras do programa a cada ano; maior ação dos agentes locais para mobilizar os agricultores para o acesso; estabelecimento de parcerias entre as principais organizações envolvidas no ambiente institucional do PRONAF no território.

Do ponto de vista da incidência territorial das políticas públicas analisadas, aponta-se para a importância da consolidação de uma rede local por onde circulam as informações sobre as políticas públicas, constituídas a partir de diferentes arranjos institucionais, a depender do município, entre técnicos das prefeituras, da EMATER, dos STRs, de organizações não-governamentais em geral, representantes dos conselhos municipais, representantes de associações comunitárias ou de grupos comunitários e, finalmente, os próprios agricultores familiares. Quanto mais articulados estiverem os nós dessa rede, mais facilmente a informação circula e chega até os agricultores, transmitindo uma maior confiança no andamento dos processos e facilitando o acesso às políticas.

\section{REFERÊNCIAS BIBLIOGRÁFICAS}

ABRAMOVAY, Ricardo. O capital social dos territórios: repensando o desenvolvimento rural. Revista Economia Aplicada, v. IV, n. 2, 2000.

CARNERIO, Maria J; MALUF, Renato. Para além da produção: multifuncionalidade e agricultura familiar. Rio de Janeiro: NEAD/UFRJ, 2003. 
D’ÁVILA, Claudia A.; SILVA, Sandro Pereira. Segurança alimentar e desenvolvimento local: uma análise dos resultados do Programa de Aquisição de Alimentos (PAA) em Minas Gerais. Revista de Políticas Públicas, v. 15, n. 2, 2011.

DELGADO, Nelson G.; LEITE, Sergio P. Políticas de desenvolvimento territorial no meio rural brasileiro. DADOS - Revista de Ciências Sociais, v. 54, nํ2, 2011.

FAO/INCRA. Diretrizes de política agrária e desenvolvimento sustentável. Brasília. Versão resumida do Relatório Final do Projeto UTF/BRA/036, 1994.

FAVARETO, Arilson. Paradigmas do desenvolvimento rural em questão. São Paulo: FAPESP, 2007.

FERREIRA, Brancolina. A agricultura familiar e o Pronaf: contexto e perspectivas. In: GASQUES, José G.; CONCEIÇÃO, Júnia C. Transformações da agricultura e políticas públicas. Brasília: IPEA, 2001.

FLIGSTEIN, Neil. The architecture of markets: an economic sociology of twentyfirst-century capítalist societies. Princeton University Press, 2001.

MALUF, Renato. Políticas agrícolas e de desenvolvimento rural e a segurança alimentar. In: LEITE, Sérgio (Org.) Políticas públicas e agricultura no Brasil. Porto Alegre: Ed. UFRGS, 2001.

MDA. Referências para uma estratégia de desenvolvimento rural sustentável para o Brasil. Brasília: MDA, 2005.

MDA. Estudo Propositivo para a dinamização econômica do Território Vale do Mucuri. Brasília: MDA, 2007.

MEJIA, Margarida R. O "território" na análise da ruralidade: reflexões elaboradas a partir da situação de um assentamento do Incra. Revista Redes, v. 11, n. 1, 2006.

OLIVEIRA, Luis F. T.; SILVA, Sandro Pereira. Mudanças institucionais e produção familiar na cadeia produtiva do leite no Oeste catarinense. Revista de Economia e Sociologia Rural, v. 50, no 4, 2013.

SILVA, Sandro Pereira. Agricultura familiar e suas múltiplas interações com o território: análise de suas características multifuncionais e pluriativas. Texto de Discussão, ㄲo 2076 Brasília: IPEA, 2015.

Avanços e limites na implementação de políticas públicas nacionais sob a abordagem territorial no Brasil. Texto de Discussão, n. 1898. Brasília: IPEA, 2014.

Mediação social e incidência territorial de políticas públicas de desenvolvimento rural no Médio Jequitinhonha/MG. Revista Cadernos Gestão Pública e Cidadania, v. $19, \mathrm{n}^{\circ}$ 65, 2014.

A abordagem territorial no planejamento de políticas públicas e os desafios para uma nova relação entre Estado e sociedade no Brasil. Revista Cadernos Gestão Pública e Cidadania, v. 17, n. 60, 2012.

Políticas públicas, agricultura familiar e desenvolvimento territorial. Revista Cadernos Gestão Pública e Cidadania, v. 16, n. 58, 2011.

Políticas públicas e agricultura familiar: uma abordagem territorial do PRONAF no Médio Jequitinhonha. Viçosa: UFV, 2008. Dissertação (Mestrado em Economia). Universidade Federal de Viçosa, 2008. 
SILVA, Marcio G.; DIAS, Marcelo M.; SILVA, Sandro Pereira. Relações e estratégias de (des)envolvimento rural: políticas públicas, agricultura familiar e dinâmicas locais no município de Espera Feliz (MG). Revista de Economia e Sociologia Rural, v. 52, nำ 2, 2014.

SOUZA, Emanuel F. M.; SILVA, Marcio G.; SILVA, Sandro Pereira. A cadeia produtiva da mandiocultura no Vale do Jequitinhonha. Revista Isegoria, n. 2, 2012.

SCHROEDER, Mônica. Plano Safra Territorial do Território Rural do Vale do Mucuri. Brasília: FCR, 2007.

UFVJM. Plano Territorial de Desenvolvimento Rural Sustentável no Território Vale do Mucuri. Relatório Final. FUNDAEPE/APTA/UFVJM, 2010. 